\title{
Future Application Trends for Health based Internet of Things
}

\author{
Albia Maqbool \\ Lecturer \\ Northern Border University \\ Rafha- 11351, \\ Kingdom of Saudi Arabia
}

\author{
Nazar Mohsin \\ Technical Solutions Consultant \\ Hewlett-Packard Globalsoft Ltd, \\ Mahadevpura City \\ Bangalore, Karnataka, India
}

\author{
Habiba Siddiqui \\ Research Scholar \\ Universiti Teknologi \\ PETRONAS \\ Perak, Malaysia
}

\begin{abstract}
This paper explores the Health related prospects in the Internet of Things (IoT). IoT is rapidly picking up the interest of people as well as in the field of Health which is the prime concern of human race. In this paper we will explore and observe the relation between health and IoT. Devices and tools of health department can be tracked by using IoT, the measurements and calculations of different health equipment are brought together by IoT. We will discuss the How IoT is revolutionizing the fields of Health department.
\end{abstract}

\section{General Terms}

Computer Science, Internet of Things

\section{Keywords}

Future Applications, Health Monitoring Applications.

\section{INTRODUCTION}

World Wide Web concept in 1990's made the evolution of technology faster and later in the 20th century mobile Internet. Now as the technology grows, we are connecting every possible thing, this leads us to an Internet revolution knows as the 'Internet of Thing's as shown in Figure 1.

IoT gives a virtual identity on Internet to every physical thing, which means everything is connected from everywhere and at any time. It denotes ecosphere where human beings, physical objects, animals, environments and virtual data all use same space and time to interrelate with each other." [1].

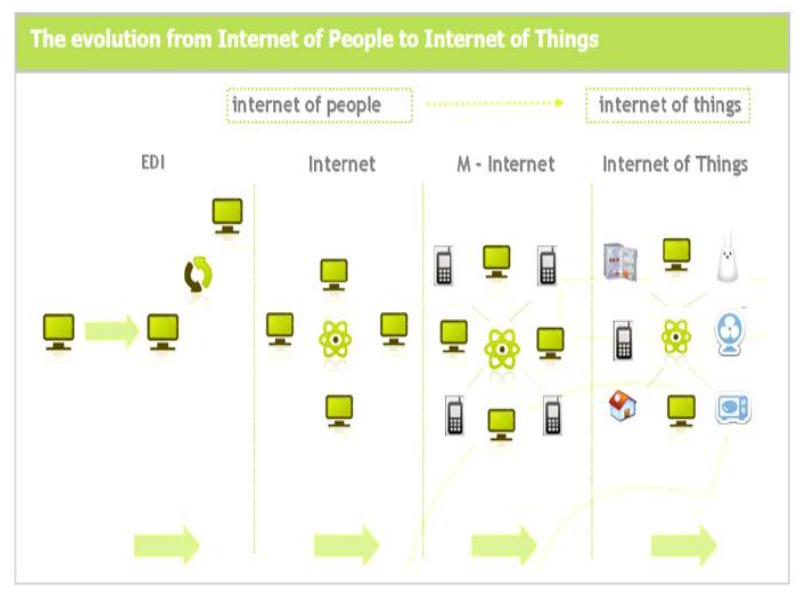

Fig. 1. Evolution of Internet of Things

The Internet of Things (IoT) was first introduced in 1999, but Radio Frequency Identification (RFID) gave a kick start to IoT and IoT became a practically possible and therefore boomed in the academia and industry. Current work on IoT clearly shows that it will become a part of our day to day life very soon. Development of IoT in communications, sensors and networking will make IoT reach every possible area.

\section{LITERATURE REVIEW}

Current Internet is in view of construction modeling with conventions, locations, and a space name plot that all together speak to center rule that limit its capacity to adjust to upgraded execution and prerequisites of unwavering quality. Later on, considering the measure of gadgets that will have admittance to it and their versatility, the Internet will have brought down the said impediments and gadgets will have the capacity to associate straightforwardly into the Internet, dispensing with boundaries, for example, nearby systems, neighborhood system switches, and area name servers [2].

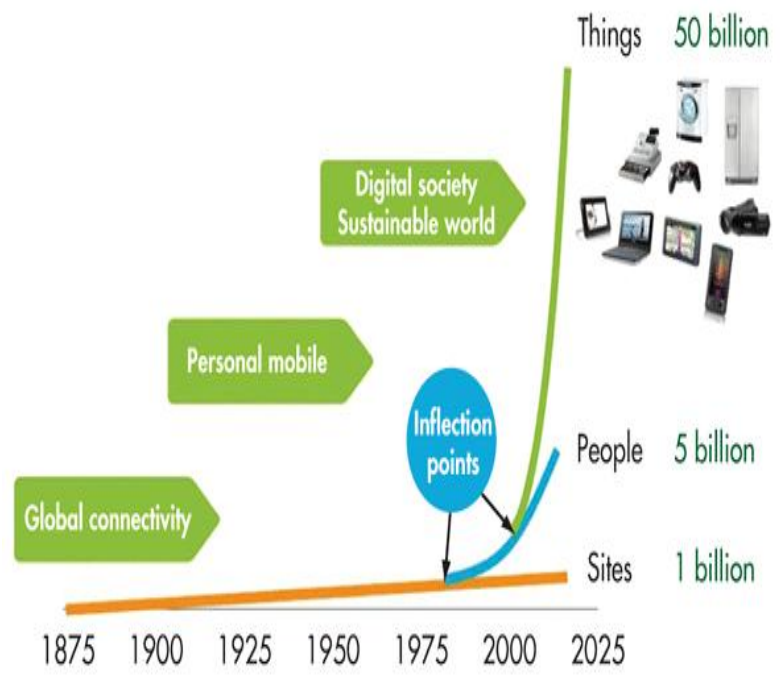

Fig. 2. Future vision for Internet of Things

This vision (see Figure 2) challenges the conventional comprehension of a system topology as a total of systems working in parallel one alongside another, and rather proposes the Future Internet as a solitary bound together system in which gadgets and parts collaborate in a more unhindered way [3].

The past definition gives an extensive variety of potential outcomes for the advantages that the Future Internet brings to the table, additionally permits to deduce the rashness of the current condition of the innovation and its market [4].

It additionally expresses the significance of the Internet of Things, expanding the part of each article around us by issuing them an improved mission of helping specifically or in a roundabout way human life by the utilization of Internet. In that way, the Internet of Things can be characterized inside the connection of the Future Internet and the advantages that it conveys to business methods and regular living: "A world where physical articles are flawlessly incorporated into the data system and where the physical items can get to be dynamic members in business methodologies and ordinary 
living. Administrations are accessible to communicate with these keen questions over the Internet, question their state and any data connected with them, considering security and protection issues" [5].

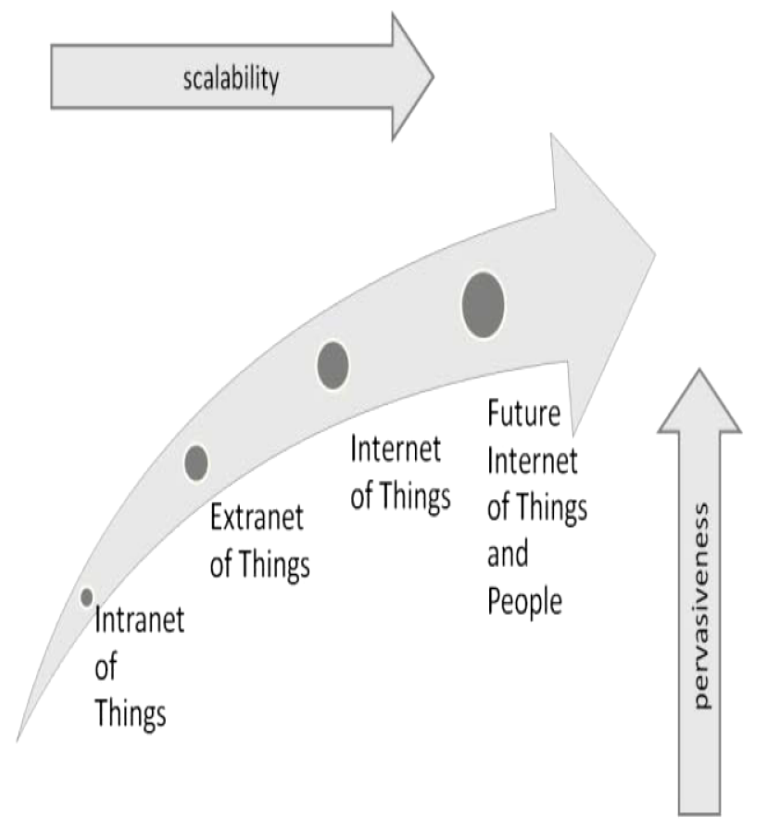

Fig 3: A Phased Approach from the Intranet of Things to a Future Vision on the Internet of Things [1]

While pervasiveness can increment with each progression on this staged development through applications and more extensive reception, adaptability and foundation necessities additionally expand and must be met.

Fig. 3 demonstrates the development stages that have prompted the idea of the Internet of Things as portrayed in past fragments. At the point when an associations private PC system utilizes Internet Protocol Technology and permits a gadget in the system to be mindful of the data and conditions of different gadgets in the system, takes after under the class of an Intranet of Things.

In the event that this same data and conditions of gadgets inside an intranet is reachable by a system hub outside the intranet taking after the decided verification and security conventions, the idea develops to Extranet of Things. Web of Things makes it a few strides further by making this communication between gadgets a various and consistent continuous movement, and by conveying the serviceability to individuals under ordinary premise.

IoT is an extraordinary open door for wellbeing division to create and assemble information from any conceivable things and spots. Various applications can be connected to the different fields of wellbeing division. Considering the enthusiasm of the elderly era to carry on with a dynamic autonomous life, the Ambient Assisted Living (AAL) field of advancement keeps on growing. AAL incorporates systems, ideas, (electronic) frameworks, items and administrations that the regular lives of more seasoned and hindered individuals bolster relying upon the circumstance and inconspicuous..

Here are a percentage of the application territories that remain to benefit most from the potential outcomes offered by the Internet of Things. Just probably the broadest classes are broke down and talked about, since from these principle ones numerous others will be conveyed. By and large all organizations will change their inside method for working, and will advance from the conventional back-office, reportarranged stage, into a genuine time systematic and information serious methodology conveying business operations to the IoT Era [9]. Notwithstanding the ones portrayed underneath, some different zones that can be extraordinarily affected by the Internet of things are Energy, Automotive and Insurance commercial ventures.

Assembling and creation courses of action can exceptionally advantage from IoT innovations [10]. By the utilization of disseminated sensors, savvy gadgets, actuators and machineto-machine correspondence creation methods can be significantly streamlined [11]. By having genuine time/ true deceivability, a more profound understanding is gotten on the distinctive parts of the assembling methodologies. It will be conceivable to have quick following of apparatus execution, material administration, enhanced quality control which would prompt expanded profitability [5]..

Likewise new conceivable outcomes emerge. For instance an organization could offer an administration of custom assembling, by which customers could remotely work hardware through an Internet based application, and create their own particular items and models. This will offer a progression of preferences to little organizations with insufficient capital or volume requests concerning putting resources into costly generation hardware [12]. These advantages are expressed obviously in the accompanying quote in Table 1 ..

Table 1. Available health or fitness devices.

\begin{tabular}{|c|c|c|c|c|c|}
\hline & Bluetooth & $\begin{array}{c}\text { Wi- } \\
\text { Fi }\end{array}$ & RFID & NFC & $\begin{array}{c}\text { Mobile } \\
\text { add-on }\end{array}$ \\
\hline $\begin{array}{c}\text { Stetho- } \\
\text { scopes }\end{array}$ & Yes & Yes & Yes & & Yes \\
\hline $\begin{array}{c}\text { Glucose } \\
\text { monitors }\end{array}$ & Yes & Yes & Yes & Yes \\
\hline $\begin{array}{c}\text { Pulse } \\
\text { oximeters }\end{array}$ & Yes & Yes & Yes & Yes \\
\hline $\begin{array}{c}\text { Heart rate } \\
\text { monitors }\end{array}$ & Yes & Yes & Yes & & Yes \\
\hline $\begin{array}{c}\text { Wrist- worn } \\
\text { (body } \\
\text { monitors) }\end{array}$ & Yes & Yes & Yes & Yes & \\
\hline
\end{tabular}

All the gadgets would offer their usefulness as a web administration. Gadget mix accordingly means administration reconciliation, concentrating on the usefulness a gadget offers and not on the specific gadget innovation. This not just makes another ideal model on the shop floor, yet it likewise would energize the advancement of new gadgets in the mechanization business that offer inserted web administrations [5]. The wide extension of the idea of Internet of Things is attainable because of the development of the related innovations, for example, Bluetooth, Radio Frequency Identification (RFID) [18] and Near Field Communication (NFC). These innovations are quickly presented in the accompanying passages for the non-expert per user who needs to end up acquainted with the advancements identified with the IoT. In addition, Table 1 displays a specimen of accessible health awareness arranged gadgets that use advancements identified with the Internet of Things. The senior per user may exclude this area and move to the accompanying one.

The present issues in inventory network administration are predominantly because of the powerlessness to settle on 
totally emphatic choices because of the absence of continuous data of distinctive parameters on the inventory network. This brings issues, for example, slacks popular estimate, value variance and Limited supply [13]. This can be fundamentally ascribed to the customary data transmission model. With the new potential outcomes brought by the Internet of Things, the conventional vertical data transmission model is broken, and these data transmission slacks can start to be illuminated [14]. Fig. 4 demonstrates a conceivable setup of an IoT framework connected to wellbeing administration.

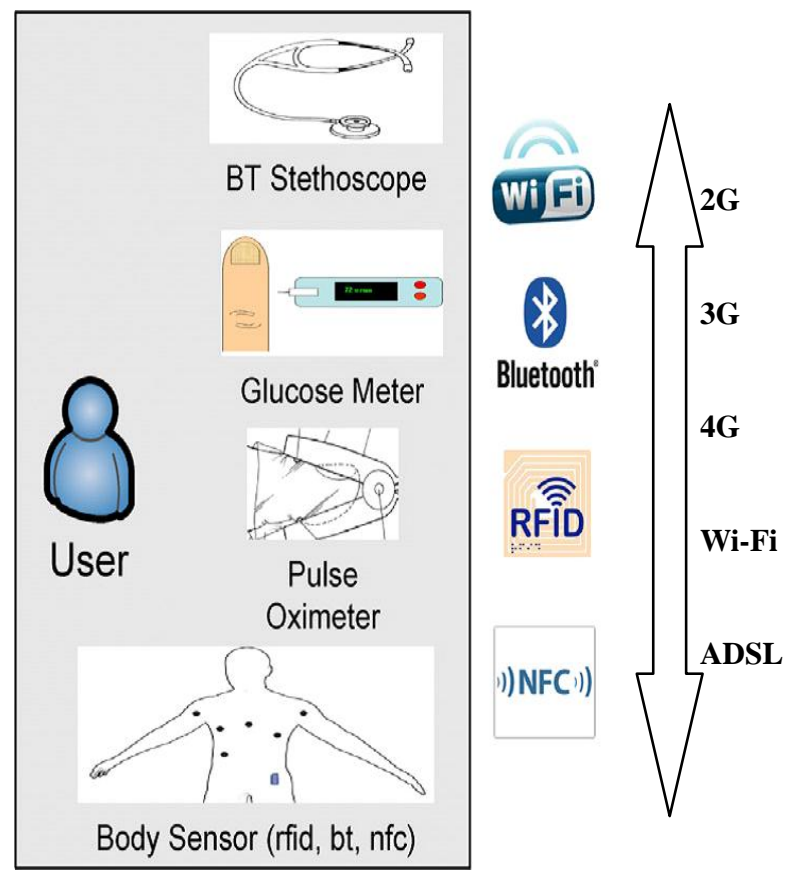

Fig. 4 IoT based Information transfer architecture

Moreover, IoT advancements bolster the uprightness and control of items by permitting following of the area and the condition of benefits all through the full item life-cycle. Complete trustworthiness of advantages in the inventory network incorporates the accompanying angles as depicted in [5]:

- Physical honesty of the item itself. Sensors can be utilized to guarantee that the item was never presented to conceivably harming ecological conditions.

- Transportation courses, watching that the item never was in a zone where it shouldn't be. Investigation of logistics, creation forms.

- Honesty of item in regards to method for creation..

In the wellbeing division, IoT advances can give advantages from two principle points of view. The principal point of view is helping methods, following meds and hardware as in the past samples. For this RFID labels are a vital innovative empowering influence. This is being done as of now by a few clinics like the Jena University clinic in Germany, which to enhance logistics methods while gives better care by following hardware, patients and prescriptions [5].

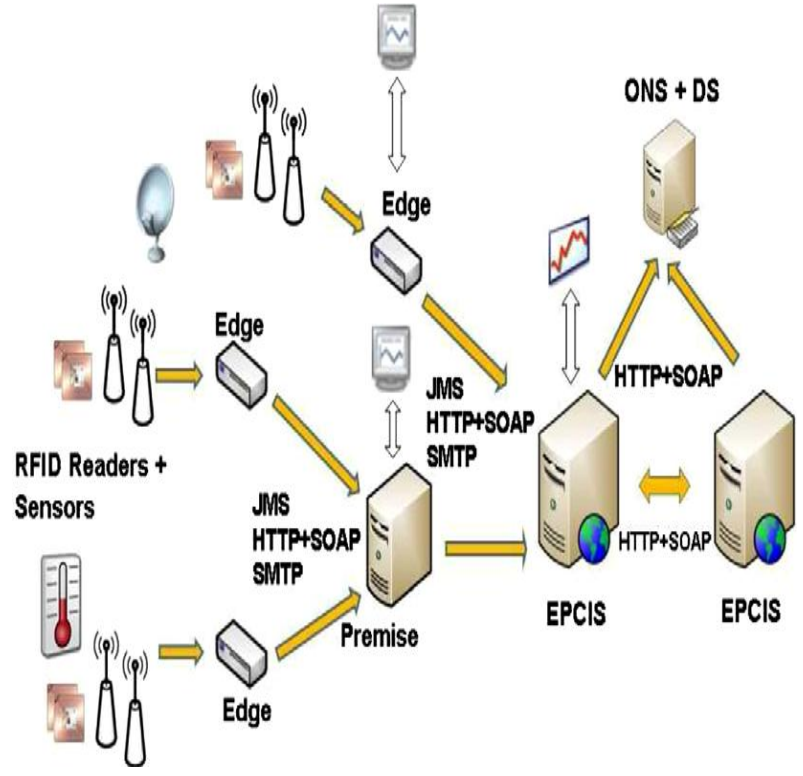

Fig. 5 Device communication between different parts of the IoT system.

- Beginning, ceasing and designing perusers.

- Designing the dispatchers keeping in mind the end goal to set the convention utilized for the transmission of use level occasion (ALE) reports in the edge and reason layers.

- Designing the destination where the reports will be sent to, and consequently the connections keeping in mind the end goal to bolster base advancement.

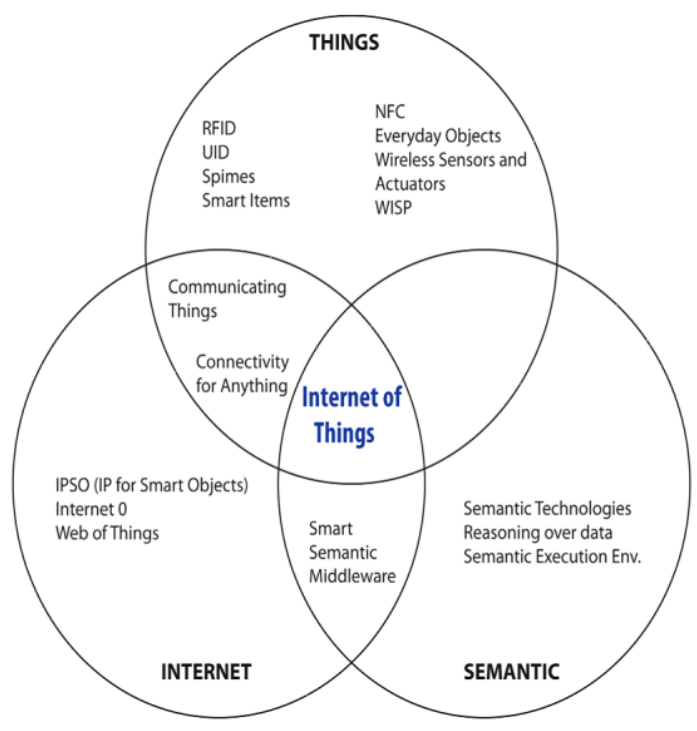

Fig. 6: Thing, Internet, Semantic-Oriented Vision [6]

The second viewpoint is by wellbeing observing and supported living (see Figure 5), which can likewise be done in spots outside healing centers by the utilization of savvy information gathering gadgets in omnipresent situations [16].

Steady correspondence integration empowered by the Internet of Things in Assisted Living Environments permits a constant assessment of the wellbeing parameters of patients, as a kind of measured self-following of crucial signs data and decided qualities given the conditions and prerequisites of particular patients. It additionally offers advantages as it goes about as a stride towards counteractive action wellbeing treatment 
instead of arrangement wellbeing measures [17]. The systems and advancements (see Figure 6) utilized are client focused, so centered around the individuals and incorporate into the quick living environment.

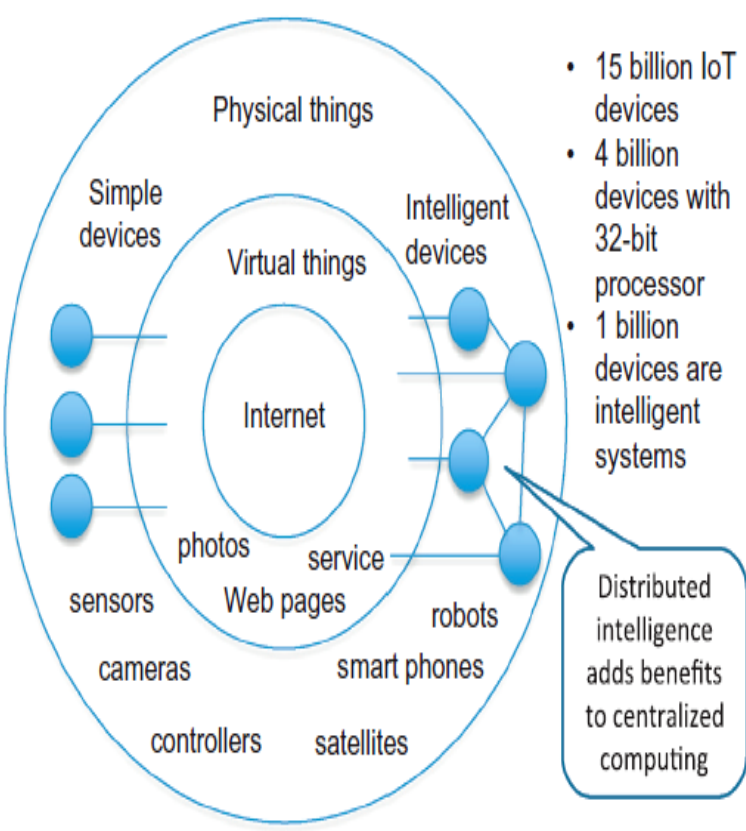

Fig. 7. Internet of Things and devices

The innovation (see Figure 7) fits sensibly to the needs of the client and not the other way around. To impart setting data advancements in the AAL environment can be helpfully secluded and can be arranged to have a pseudo- astute conduct. Then again, this highlight is not required. A few illustrations in which the Internet of Things is connected in the Health division are GymSkill, ModiMed and so on.

The Internet of Things (IoT) will change all the parts of living style of a person. Consistently strength of each individual will be checked by utilizing encompassing sensors, wearable. Normal checking of wellbeing will help in overcome endless illnesses utilizing body sensors and key signs sensors [2].

Notwithstanding getting up can help individuals in need are calmed in the programmed open screens and warming at indicated times goes into operation. The wellbeing can be enhanced if clever smoke finders also counsel with flame suspected relatives or neighbors. Moves around evening time something about the flat or the house is with music, lights and TV reenacts that somebody is home. In a generally selflearning framework sensors (see Figure 8) are organized and their information combined and dissected, whereby, for instance, routine undertakings can be performed. On the off chance that the occupants debilitated or overpowered, "shrewd" framework offers age-suitable support to, makes proposals for critical thinking, incorporates outside administration suppliers, (for example, security organizations or telemedicine focuses) with one or even settle a crisis message. AAL administrations are as often as possible developed separately. In the particular VDE-AR-E 2757-2 Service Living at home - Requirements for consolidated administrations supplier is an illustration of the telemedicine key signs observing joined with the situation office related administrations depicted.

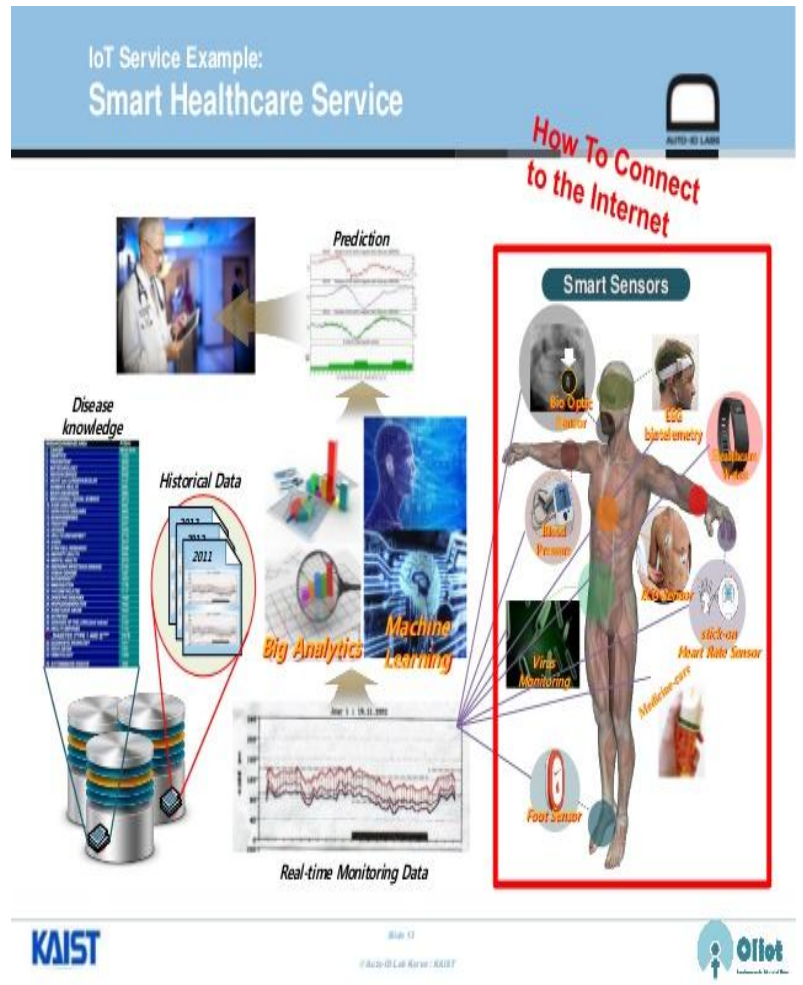

Fig. 8. IoT and Smart Healthcare Service

\section{HEALTH BASED IoT}

\subsection{LISA}

LISA a venture just focus on Ambient Assisted Living (AAL) by division of Building and Robotic Implementation at The Technical University of Munich. AAL is a stage which screens and controls the day by day life parts of elderly individuals. Habitually said application samples exist in the field of security, solace and amusement. These incorporate the programmed shutdown of the stove without defensive measures against break-ins and also setting ward lighting, room temperature or music control, which are adjusted to the propensities for the client. Especially imperative for Ambient Assisted Living is the likelihood of killing, for example, the Smart Home Platform Qivicon by tapping on the Smartphone all lights, radiators and other electrical apparatuses.

Notwithstanding getting up can help individuals in need are mitigated in the programmed open screens and warming at indicated times goes into operation. The wellbeing can be enhanced if canny smoke indicators also counsel with flame suspected relatives or neighbors. Moves during the evening something about the loft or the house is with music, lights and TV reproduces that somebody is home.

Notwithstanding getting up can help individuals in need are mitigated in the programmed open screens and warming at indicated times goes into operation. The wellbeing can be enhanced if canny smoke indicators also counsel with flame suspected relatives or neighbors. Moves during the evening something about the loft or the house is with music, lights and TV reproduces that somebody is home. 


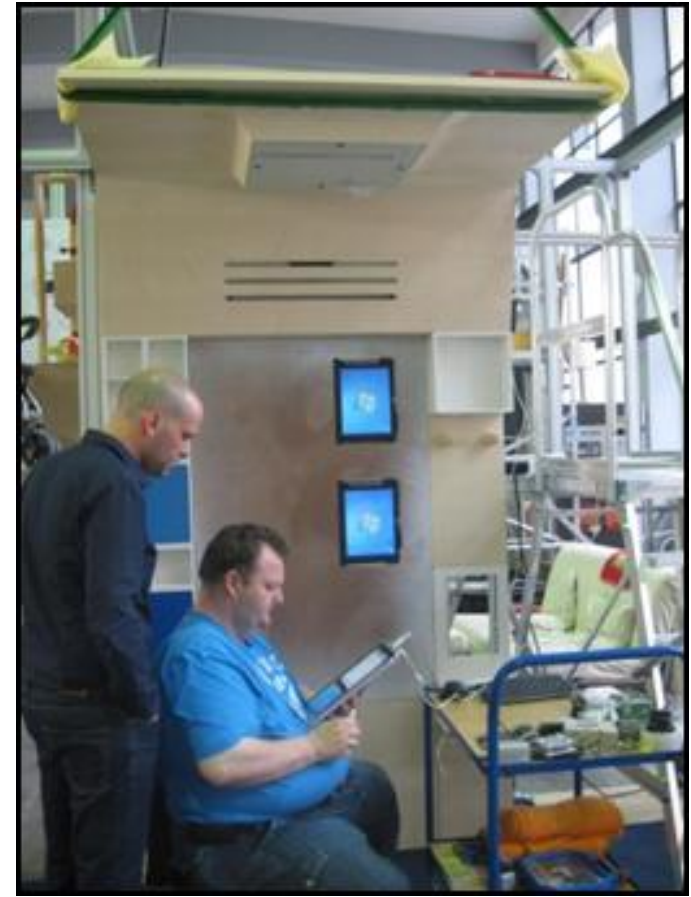

Figure 9: LISA - Mockup at the Technical University of Munich. [11]

Maturing of society raises a worry about day by day living and day by day living exercises got to be hard for elderly individuals. Maturing society needs novel ways to deal with get legitimate administration and to determine regular issue. Exercises of Daily Living (ADLs) are considered as a standout amongst the most critical examination zone and bunches of work is going around this. Around there diverse innovations are consolidated to make a framework that could upgrade and creatively help maturing society regular living quality.

ADLs were upheld by a novel Robotic Service Wall in LISA venture. Each framework parts offer "attachment and play" highlights and secluded framework is trailed by proposed framework. This framework is all that much productive and adaptable, which can be set and reset into different exact setups, and can be sent in wherever without obliging any careful space estimations [3].Mockup of this framework is exhibited in Figure 9.

Security and assurance is imperative to stay away from the wellbeing bargains of patients in pharmaceutical items field [2]. Quality controlling of medications could be possible by including a keen mark as RIFD or related innovation with medications all through the inventory network methodology and also forging can be keep away from..

\subsection{GYMSKILL}

Technical University of Munich created another item named Gymskill. It is a Smartphone-based fitness coach, which is utilized to screen the workout done by the client exhibited in Figure 10 and 11. Advanced cell's implanted detecting abilities is used in this framework to screen the workout by setting it on the parity board (spinner and accelerometer). The skill of the learner is evaluated via naturally investigating the information by framework.

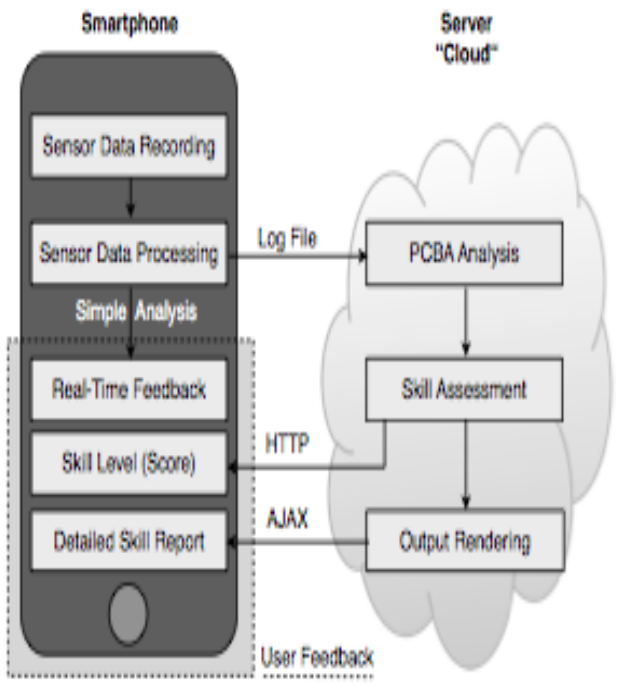

Fig. 10 Overview of the GymSkill System
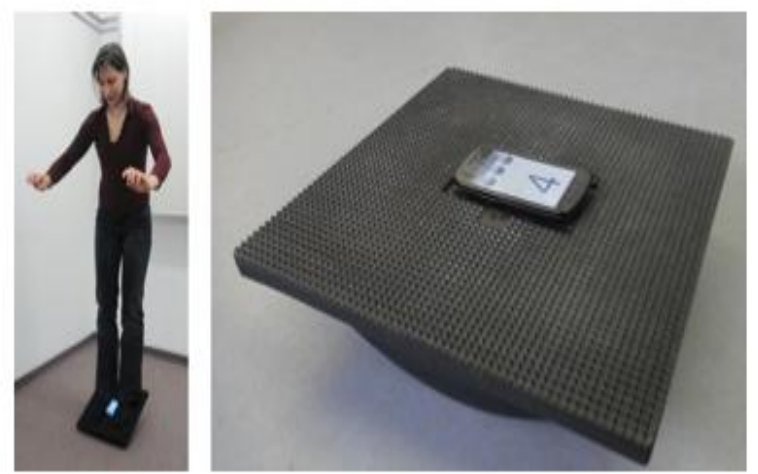

Figure 11: Real Time Use of GymSkill.

Essential input as sound or feature is given by framework to execute intelligent programmed evaluations of the performed workout quality. This framework conveys an overall quantitative finish of physical workout as a consolidated capacity metric, which is the establishment for sensible evaluations of physical workout. Subsequently, it gets to be ideal for following individual improvement all through a long haul preparing project [4].

\subsection{MobiMed}

Mölleret. Al. [5] presented a framework named MobiMed, a medicine pack identifier applying four association models: content pursuit, examining, touching, and indicating. Visual inquiry is utilized as a part of this framework to recognize the precise data by simply checking the medication parcel of the pharmaceutical. This will make ID and investigation of any medication simple to client and can prompt an effective selfbenefit in the field of drug. Infidelity of medications will be forestalled with the utilization of this framework. Client simply needs a Smartphone with a cam and an application introduced in it and a web association. IoT advances are useful to wellbeing division in two ways. Initial one is following gear and meds and supporting procedure. RFID tag is the best innovative route for accomplishing this objective. This is as of now actualized by couple of healing centers, for example, the Jena University doctor's facility in Germany. In clinic IoT helps in enhancing logistics methodologies and 
conveys better administration by following patients, gear, and solutions [6].

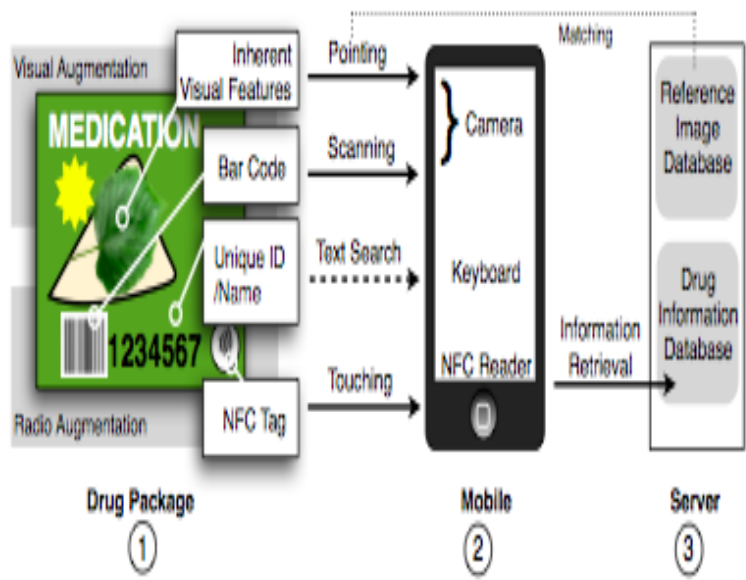

Fig. 12 Overview of the MobiMed System

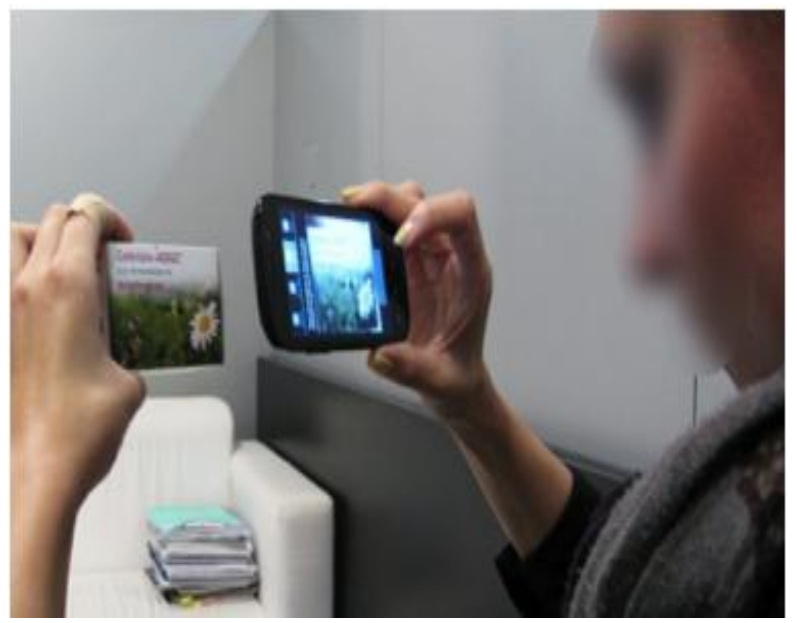

Fig. 13: Getting information about medicine using MobiMed.

The second route is by helped living and wellbeing observing, this can be attained to by introducing keen information gathering gadgets in the spots where individuals visit every now and again [7, 27]. Web of Things empowered Constant correspondence integration for continuous wellbeing assessment of patients in Assisted Living Environments. Information assembled by distinctive social affair gadgets will help in investigating the crucial indications of ailments in right on time arranges so patients can be conceded and cured with in time [8].

\subsection{RFID-based assistive devices}

A fundamental RFID-based application is the route framework. It helps visually impaired individuals discover some way or another in a new region. RFID labels are appropriated through the region. They can for instance be set in the focal point of the walkways to arrange the visually impaired individual and forestall conceivable falls close to the fringe of the walkway [9, 24]. The RFID stick (see Figure 14) has a label peruser with a receiving wire that emanates radio waves; the labels react by sending back their put away information, henceforth recognizing the area of the visually impaired individual. The label peruser (RFID stick) transmits through Bluetooth or ZigBee the information read from the RFID label, which incorporates the label ID string [10, 24]. This information is sent from the checking station through the system layer to the RFID server of the application layer. The visually impaired individual can record the destination's name as a voice message utilizing the checking station. Headings are gotten by the checking station and played as voice messages [11, 24].

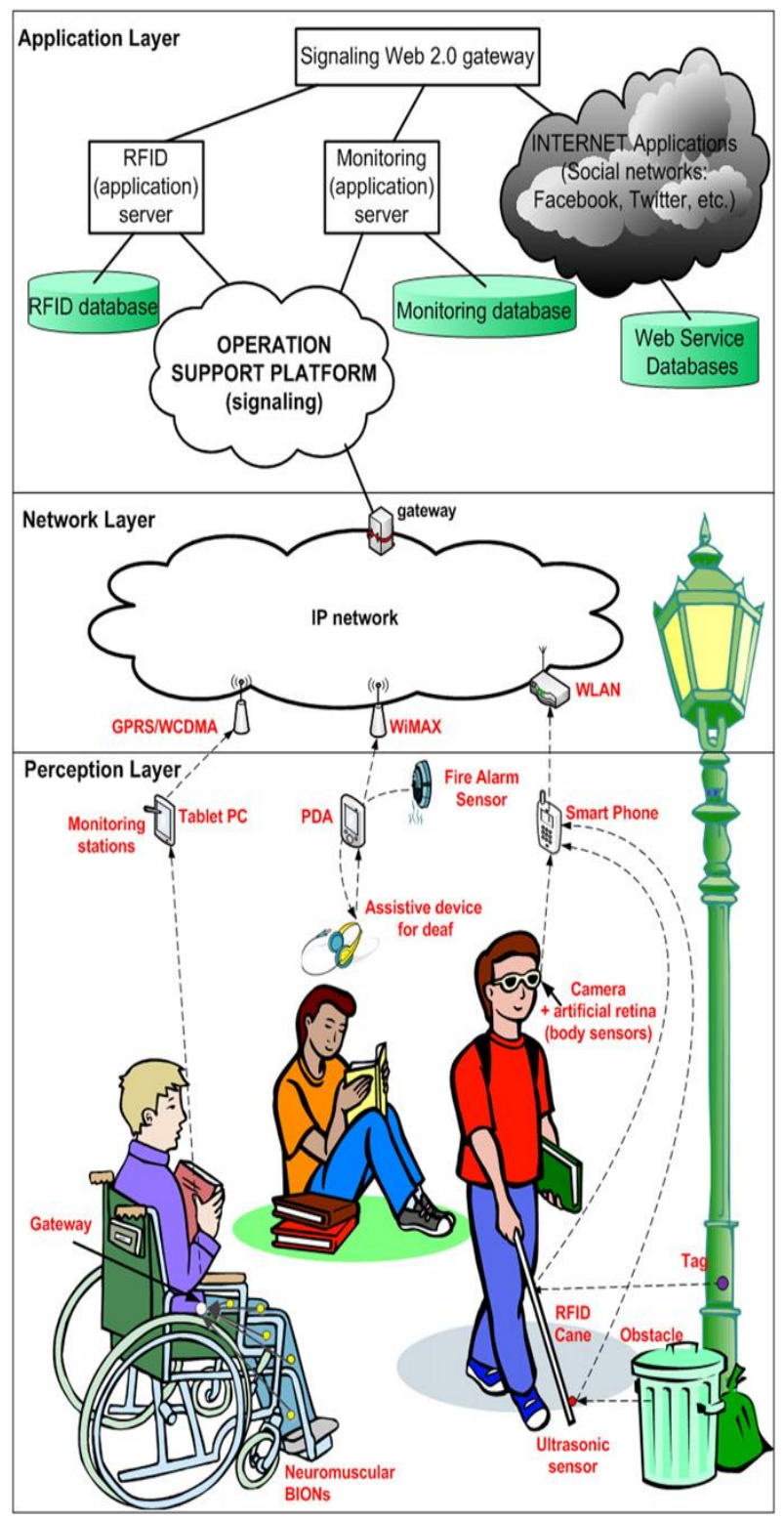

Fig.14 Future architecture of health based IoT

A snag discovery framework in view of a ultra-sonic sensor can likewise be included $[15,24]$. The sensor is mounted on the RFID stick to amplify its compelling range and see impediments the stick alone would not have the capacity to identify, (for example, a junk can in Figure. 14). A voice message played at the observing station cautions the outwardly debilitated when a snag is identified. A various sensor-based shoe-mounted sensor interface is likewise grown in $[16,24]$ as a supplementary gadget to the stick to 
distinguish obstructions inside $61 \mathrm{~cm}$ in front of the outwardly disabled.

A boundless methodology for outside route depends on Global Positioning System (GPS).It does not oblige labels to work. Then again, its determination is constrained (couple of meters) and it can't work legitimately inside. Thusly, some route frameworks for the outwardly disabled coordinate both advances (RFID and GPS) [17, 24].

\subsection{Body sensors, actuators and neuro- chips.}

Body sensors and actuators can be helpful to perform useful vivification of incapacitated appendages. Sensors joined to the nerves can distinguish the client's plan to move certain muscles and actuator sweep empower these muscles to restore the capacity to move. A disabled can be outfitted with neuromuscular smaller scale inserts named BIOnic Neurons (BIONs) $[18,24]$, which are separately composed remote cases that can be infused at a few locales in the body close engine nerves. Their fundamental capacity is to vivify deadened appendages..

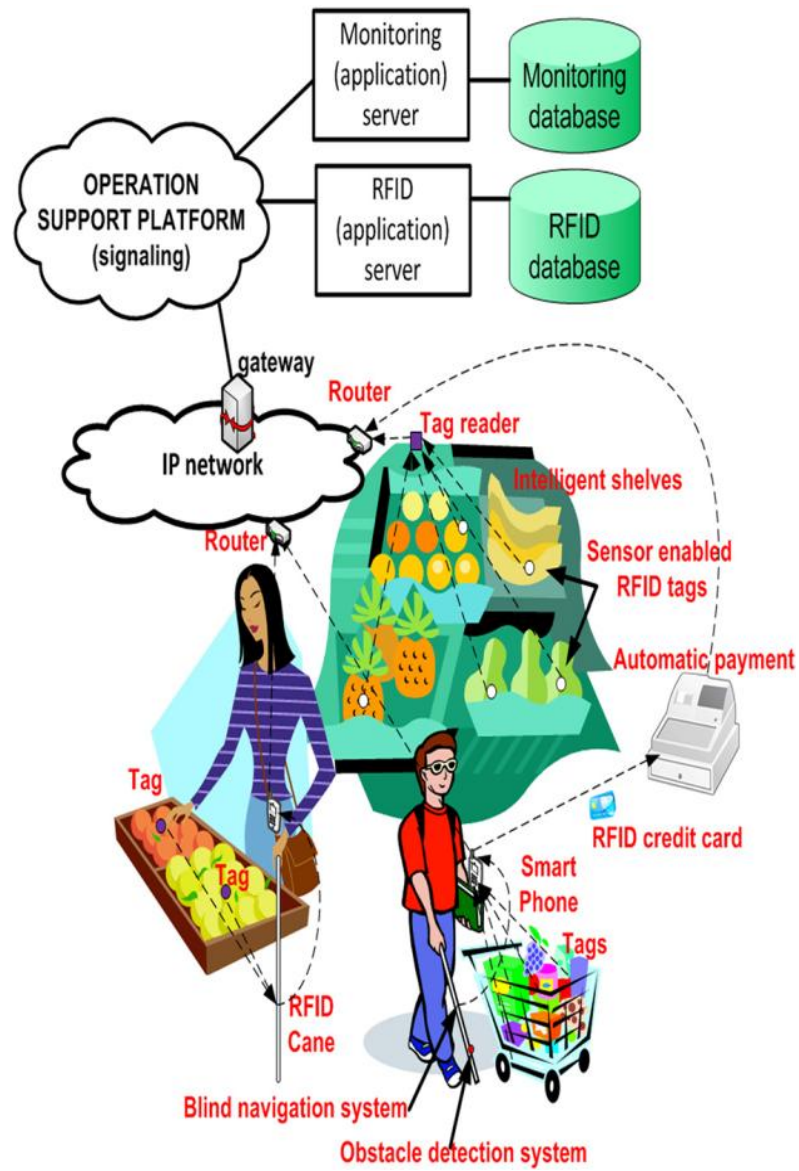

Fig. 15 Future of health based IoT for shopping

They get force and advanced charge information from an outer radio recurrence loop and convey fortifying current heartbeats to select the engine neurons and actuate related muscles. Sensors are needed by the BION to recognize deliberate order signals and to give tangible criticism to control neuromuscular incitement. This innovation is utilized to make developments in appendages deadened by upper engine neuron issue, for example, spinal string harm and stroke. BIONs perform Functional Electrical Stimulation (FES),a procedure that uses electrical streams to enact nerves innervating limits influenced by loss of motion. Thusly, engine capacities are recouped. A few samples of FES applications include the utilization of neuroprostheses that permit individuals with paraplegia $[19,24]$ to stand, walk, or restore hand handle work in individuals with quadriplegia.

In this shopping situation, individuals with visual debilitations shop self-sufficiently (see Figure. 15). The visually impaired route framework helps them to discover some way or another in a store. The store's RFID framework can utilize programming to guide the outwardly disabled in shopping. In $[20,24]$, a RFID-tag based route framework is proposed. The grocery store is partitioned into cells containing a rack and section way cells. RFID labels are circulated through the floor.

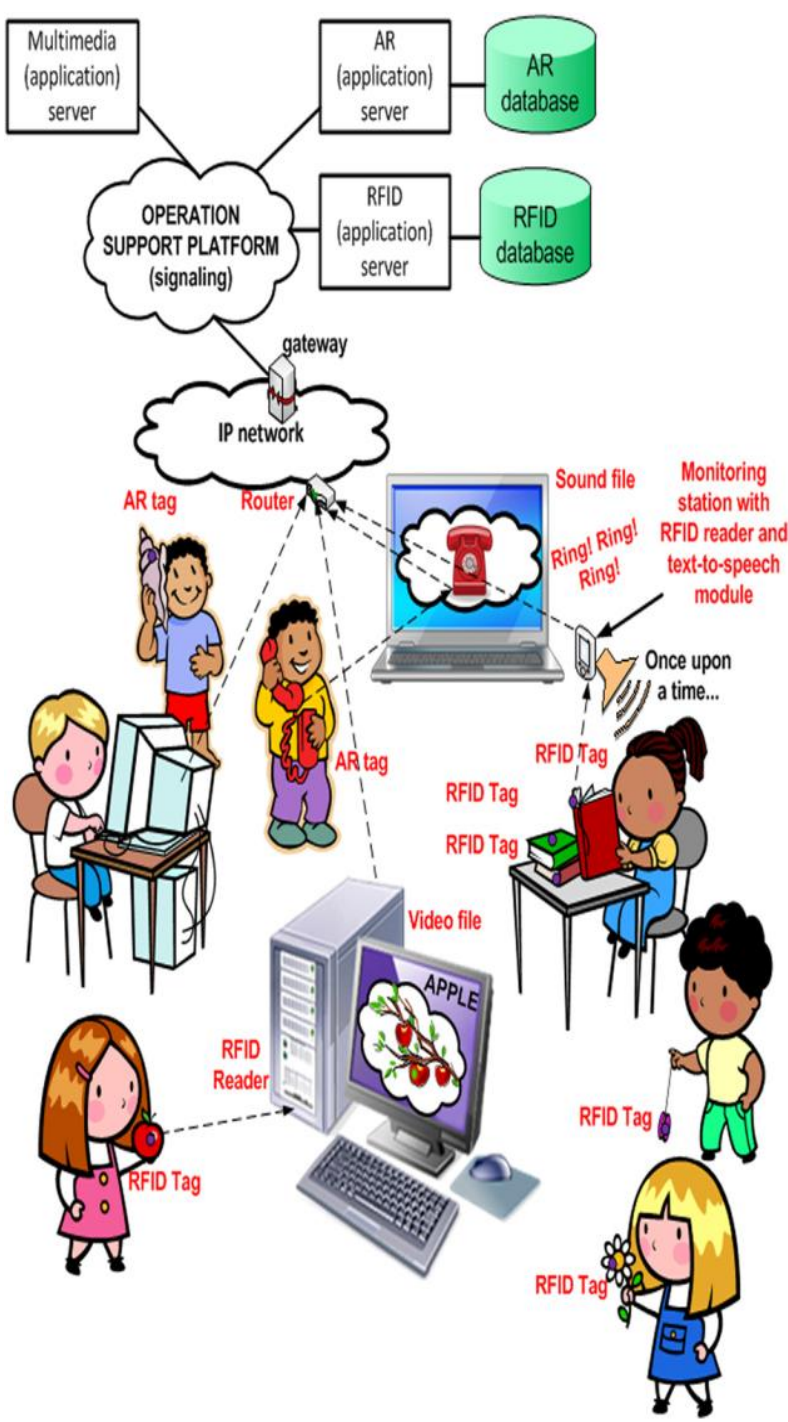

Fig. 16 Future of health based IoT in school

The label IDs with in a phone are mapped to route data, for example, the sort of a given cell and the sorts of neighboring cells. The checking station (Smartphone) keeps up a Bluetooth association with the RFID peruser (savvy stick) of the client to stay informed regarding his/ her position whenever utilizing the mapping of label IDs with route data. The discourse combination and acknowledgment module of the observing station (Smartphone) empowers the outwardly disabled individual to say the area of the store where he/she 
need to go. The course to take after is gotten summoning web benefits through a WLAN joined with the Internet. As the outwardly debilitated strolls, steering headings from an android application are gotten through the earphone of the PDA and played as voice messages.

The school situation is indicated in Figure 16. The creators in $[21,24,25]$ demonstrate the considerable included benefit of planning astute intelligent play and learning situations for little children (from one and half to four years of age) with various inabilities to fortify their dialect and relational abilities. These play and learning frameworks incorporate RFID innovation to distinguish distinctive materials, (for example, a kid's toy sheep). Then again, RFID-labeled toys are utilized to help hard of hearing children ages three to four figure out how to utilize communication through signing [23, 26]. The product created empowers a kid to utilize a RFID peruser to sweep a thing's label, catch the one of a kind recognizing number and send it to the PC's product through the USB association.

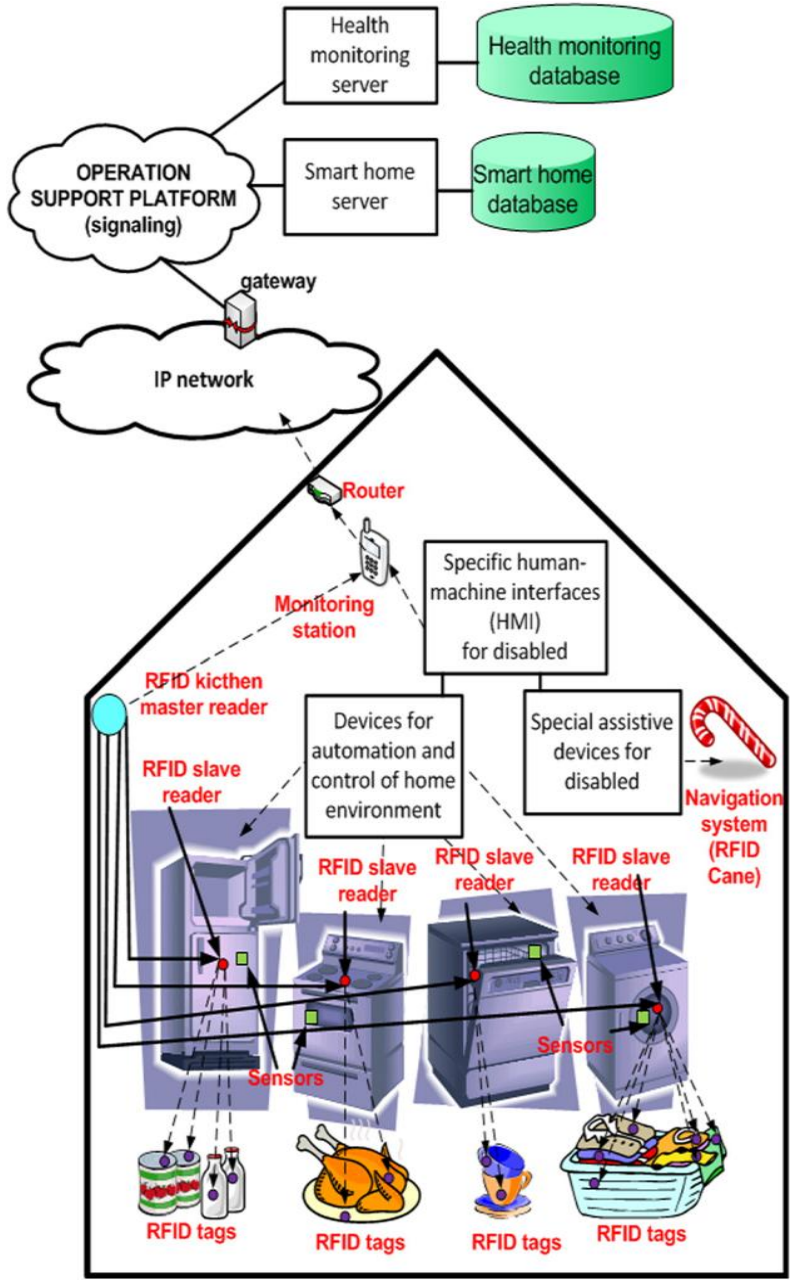

Fig. 17 Future of health based IoT for home

Keen home innovation (see Figure 17) alludes to the joining of innovation and administrations through home systems administration for a superior nature of living. Keen homes empower the robotization and control of the home environment utilizing various gadgets, for example, programmed kitchen hardware, light and entryway controllers, indoor temperature controllers, water temperature controllers and home security gadgets $[22,23,24]$. These home gadgets for computerization and control are shaped by sensors and actuators implanted in merchandise, home machines or furniture. The sensors screen the natural conditions; procedure gathered in arrangement and chips in with different units through a remote system. The gathered data is then handled by a server to give suit capable administrations to the client. On the off chance that occasions that offer ascent to caution conditions are recognized, actuators are activated for taking care of the present crisis circumstance (e.g. thief or flame caution).

\section{CONCLUSION}

Wellbeing is the most former thing in every part of life and IoT will help us to improve the wellbeing frameworks and better in future. Numerous work on wellbeing and IoT is going on, we have explored some in this paper. IoT can help us to accumulate continuous information from all over the place and whenever, which will bring about the development of right on time recognition examples of any wellbeing issue. Checking is likewise exceptionally gainful, which is diminishing the human blunders in dispersing drugs furthermore synchronizing the patient and restorative staff prerequisites. IoT is likewise in our Smartphone's presently, so it additionally gives an alternative of self-support of individuals, everybody can undoubtedly identify the ordinary issue and can utilize MobiMed and related frameworks to get the best possible solution. In the wake of dissecting distinctive systems and items grew under IoT for wellbeing division, it is all that much unsurprising that in future IoT will be all that much beneficial for individual's wellbeing and handicap individuals.

\section{ACKNOWLEDGMENTS}

The authors would like to acknowledge Dr. Naseer Ali and Faculty of Sciences at Northern Border University for the comments provided while preparing this work.

\section{REFERENCES}

[1] Santucci, G.: The internet of things: Between the revolution of the internet and the metamorphosis of objects. 23

[2] Sundmaeker, H., Guillemin, P., Friess, P., Woelfflé, S.: Vision and challenges for realising the internet of things. CERP-IoT, European Commission, Luxembourg (2010)

[3] Bock, T.: Lisa smart walls

[4] Möller, A., Scherr, J., Roalter, L., Diewald, S., Hammerla, N., Plötz, T., Olivier, P., Kranz, M.: Gymskill: Mobile exercise skill assessment to support personal health and fitness. In: Ninth International Conference on Pervasive Computing (Pervasive 2011), Video Proceedings, San Francisco, CA, USA (June 2011)

[5] Möller, A., Diewald, S., Roalter, L., Kranz, M.: Mobimed: comparing object identification techniques on smartphones. In: Proceedings of the 7 th Nordic Conference on Human-Computer Interaction: Making Sense Through Design. NordiCHI '12, New York, NY, USA, ACM (2012) 31-40

[6] Haller, S., Karnouskos, S., Schroth, C.: The internet of things in an enterprise context. In Domingue, J., Fensel, D., Traverso, P., eds.: Future Internet FIS 2008. Volume 5468 of Lecture Notes in Computer Science. Springer Berlin / Heidelberg (2009) 
[7] Istepanian, R.S.H., Sungoor, A., Faisal, A., Philip, N.: Internet of m-health things. In: Assisted Living 2011, IET Seminar on. (april 2011) 1 -3

[8] Davie, B., Florance, V., Friede, A., Sheehan, J., Sisk, J.: Bringing health-care applications to the internet. Internet Computing, IEEE 5(3) (may/jun 2001) $42-48$

[9] Intel: The internet of things (2012)

[10] Haller, S., Karnouskos, S., Schroth, C.: The internet of things in an enterprise context. Future Internet-FIS 2008 (2009) 14-28

[11] Atzori, L., Iera, A., Morabito, G.: The internet of things: A survey. Computer Networks 54(15) (2010) 2787-2805

[12] Associati, C.: The evolution of internet of things. (February 2011) 16

[13] Sundmaeker, H., Guillemin, P., Friess, P., Woelfflé, S.: Vision and challenges for realising the internet of things. CERP-IoT, European Commission, Luxembourg (2010)

[14] Roalter, L., Möller, A., Diewald, S., Kranz, M.: Developing Intelligent Environments: A Development Tool Chain for Creation, Testing and Simulation of Smart and Intelligent Environments. In: Proceedings of the 7th International Conference on Intelligent Environments (IE). (july 2011) 214-221

[15] Möller, A., Kranz, M., Huitl, R., Diewald, S., Roalter, L.: A mobile indoor navigation system interface adapted to vision-based localization. In: Proceedings of the 11th International Conference on Mobile and Ubiquitous Multimedia. MUM '12, New York, NY, USA, ACM (2012) 4:1-4:10

[16] Cirillo, M.: Proactive assistance in ecologies of physically embedded intelligent systems: A constraintbased approach. (2011) 534-538

[17] Alendal, M.: The social web of things - a social network for your devices

[18] C. Perera, A. Zaslavsky, P. Christen, and D. Georgakopoulos, "Context Aware Computing for The Internet of Things: A Survey" IEEE Communications Surveys \& Tutorials, 2013, pp. 1-41
[19] J. Sathish Kumar and Dhiren R. Patel, "A Survey on Internet of Things: Security and Privacy Issues" International Journal of Computer Applications 2014 vol. 90 no. 11 pp. $20-26$

[20] M u Farooq, Muhammad Waseem, Sadia Mazhar, Anjum Khairi and Talha Kamal. Article: A Review on Internet of Things (IoT). International Journal of Computer Applications 113(1):1-7, March 2015

[21] Marwah, Qudsia Mateen and Mehreen Sirshar. Article: Software Quality Assurance in Internet of Things. International Journal of Computer Applications 109(9):16-24, January 2015

[22] Aadhityan A. Article: A Novel Method for Developing Robotics via Artificial Intelligence and Internet of Things. IJCA Proceedings on National Conference on Future Computing 2014 NCFC 2014(1):1-4, January 2014

[23] M u Farooq, Muhammad Waseem, Anjum Khairi and Sadia Mazhar. Article: A Critical Analysis on the Security Concerns of Internet of Things (IoT). International Journal of Computer Applications 111(7):16, February 2015.

[24] Mari Carmen Domingo, An overview of the Internet of Things for people with disabilities, Journal of Network and Computer Applications, Volume 35, Issue 2, March 2012, Pages 584-596, ISSN 1084-8045,

[25] Luigi Atzori, Antonio Iera, Giacomo Morabito, The Internet of Things: A survey, Computer Networks, Volume 54, Issue 15, 28 October 2010, Pages 27872805, ISSN 1389-1286,

[26] Daniele Miorandi, Sabrina Sicari, Francesco De Pellegrini, Imrich Chlamtac, Internet of things: Vision, applications and research challenges, Ad Hoc Networks, Volume 10, Issue 7, September 2012, Pages 1497-1516, ISSN 1570-8705

[27] Khalid El Gholami, Kun-mean Hou and Najib Elkamoun. Article: Enhanced Superframe Structure of the IEEE802.15.4 Standard for Real-time Data Transmission in Star Network. International Journal of Computer Applications 51(15):26-32, August 2012. 